\title{
Erratum to: Environmental conditions modulate plasticity in the physiological responses of three plant species of the Neotropical savannah
}

Vinícius Coelho Kuster ${ }^{1}$ - Silvana Aparecida Barbosa de Castro ${ }^{1}$. Fernando Henrique Aguiar Vale ${ }^{1}$

Published online: 8 April 2017

(C) Franciszek Górski Institute of Plant Physiology, Polish Academy of Sciences, Kraków 2017

\section{Erratum to: Acta Physiol Plant (2017) 39:103}

DOI 10.1007/s11738-017-2399-4

Unfortunately, Fig. 7 has been incorrectly published in the original version. The correct version of Fig. 7 is updated here.

The online version of the original article can be found under doi:10.1007/s11738-017-2399-4.

Vinícius Coelho Kuster

viniciusck_bio@hotmail.com

1 Instituto de Ciências Biológicas, Universidade Federal de Minas Gerais (UFMG), Avenida Antônio Carlos, n 6627 , Pampulha, Belo Horizonte, MG CEP: 31270-901, Brazil 


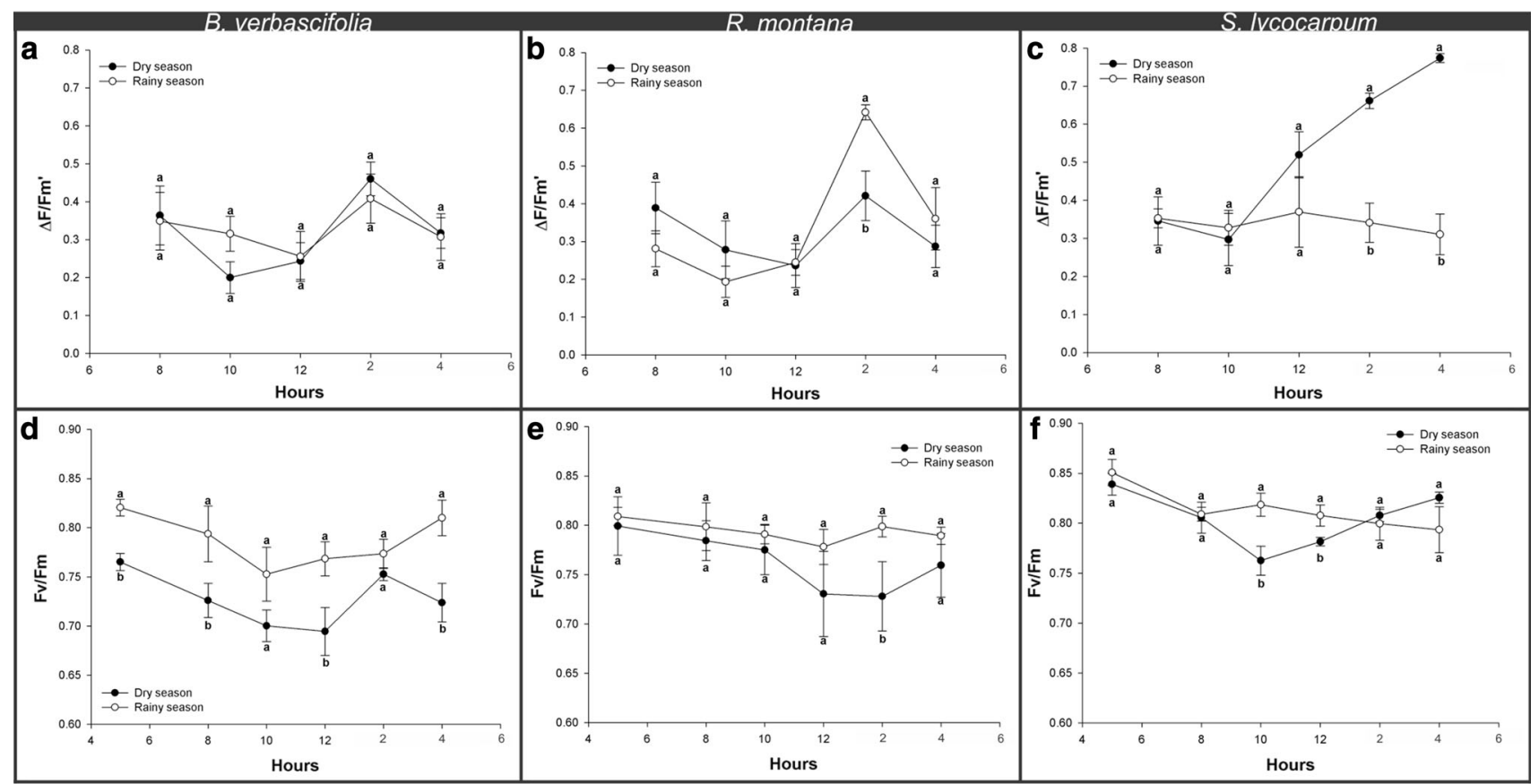

Fig. 7 Averages of the effective $\left(\Delta F / F_{\mathrm{m}}{ }^{\prime}\right)(\mathbf{a}-\mathbf{c})$ and potential dry seasons of the Neotropical savannah. Means followed by the same quantum yield $\left(F_{\mathrm{v}} / F_{\mathrm{m}}\right)(\mathbf{d}-\mathbf{f}) \pm$ standard error of $B$. verbascifolia $(\mathbf{a}$, letter do not differ statistically 